this varied between tools and type of exposure. Correlations between the measurement results and tool predictions also varied with tool and exposure type. Furthermore, a wide range of exposure estimates were observed when different users were asked to apply the same tools to the same scenario conditions.

Conclusion Models to estimate exposure and risk are essential elements of the toolbox of occupational hygienists and risk assessors and managers. However, there is increasing evidence that performance varies between tools, type of exposure and scenario conditions. More importantly, users appear to struggle to apply the tools consistently, leading to wide ranges in estimated exposures. There is an urgent need for the development and implementation of generic quality control procedures for use of exposure tools, to reduce the large uncertainties when applying these tools, both to prevent workers from being excessively exposed and unnecessarily implementation of stringent exposure control measures.

\section{A QUASI EXPERIMENTAL UNCONTROLLED BEFORE- AFTER STUDY TO ASSESS IMPACT OF CASHE INTERVENTIONS IN THE YEAR 2016-2017 AT PETROCHEMICAL INDUSTRY}

${ }^{1} \mathrm{P}$ Shah*, ${ }^{2} \mathrm{R}$ Rajesh, ${ }^{1} \mathrm{P}$ Dave. 'Reliance Industries Limited, Dahej Manufacturing Division, Bharuch, Gujarat, India; ${ }^{2}$ Reliance Industries Limited, Mumbai, Maharashtra, India

\subsection{6/oemed-2018-ICOHabstracts.1025}

Introduction To inculcate best practices in the field of $\mathrm{OH}$; RIL has launched the initiative in 2003 known as CASHe in all 7 manufacturing sites. The various interventions under this project are excellent examples of team work of medical, safety, environment and technical department of respective manufacturing sites. Previously there wasn't any scientific research approach to evaluate their outcomes at RIL-DMDwhich is amongst the largest petrochemical site of RIL. So the present study was carried out to address this need.

Methods There are total 12 manufacturing plants and each of them were considered as a unit of the study. The secondary data from all these 12 plants were collected going 1 year retrospectively using semi-structured proforma regarding various CASHe interventions and compiled using MS Excel 2007. Data triangulation was done using $\mathrm{OHC}$ data (IH Surveys and HMIS) with plant data. After necessary editing and exclusion (i.e. projects lacking before-after data, qualitative data) student paired $\mathrm{T}$ test was applied to find out statistical significance.

Result There were total 187 interventions (mean-15.58/plant) addressing noise, heat, chemical exposure, ergonomics, safety and environmental hazards. Out them 142 completed and 45 in progress. Total 3316 persons (928 employee and 2388 contract workers) trained for different $\mathrm{OH}$ training with average 600 man hours/department. Central theme for CASHe: 20162017 achieved statistically significant result in term of reduction in no. of Pre-diabetic cases up to $30 \%$ compared to previous year. Other significant interventions were reduction in exposure to benzene vapour by vapour recovery unit $(p=0.01)$, noise $(p=0.001)$ and heat etc.

Discussion CASHe projects outcomes were successful in terms of reducing hazards, workplace improvements and wellness of employee. So the present study experiments guide other industries to deal with noise, heat, highly toxic material safely and reduce their exposure along with taking care of life style diseases of their employees.

\section{6 MAKING WORKPLACE HEALTHY \& SAFE THROUGH INNOVATIVE \& SUSTAINABLE CASHE PROGRAM (CHANGE AGENTS FOR SAFETY HEALTH \& ENVIRONMENT)}

${ }^{1}$ Bhavesh Khodadiya*, ${ }^{2} \mathrm{R}$ Rajesh. ${ }^{1}$ Reliance Industries Ltd., Jamnagar, India (Superintendent Medical Officer); ${ }^{2}$ Reliance Industries Ltd., Mumbai, India (Group Medical Advisor)

\subsection{6/oemed-2018-ICOHabstracts.1026}

Introduction Reliance Industries Jamnagar Manufacturing Division is world's largest refining hub. CASHe is an innovative program with a proactive preventive approach comprising team work of Medical, Safety, Environment and Technical department helps to bring positive change and continual improvement in occupational health practices. This helps to steer plant management in a focused way to look into the work place hazards and take appropriate control measures.

Methods CASHe program has defined annual road map which comprises formation of CASHe Team, field visit, $\mathrm{IH}-\mathrm{OH}$ survey, submission of project charter, monthly CASHe team meetings with progress reports, midyear project review, final survey with report submission and plant inter-site competition for evaluation. Multidisciplinary CASHe team continuously work on this road map to achieve project goals.

Result In $2016-17$, Total 302 projects out of 408 were completed $(74 \%)$. To inculcate best projects like Chemical Exposure reduction from $2.64 \mathrm{PPM}$ to 0 PPM (close loop sampling system at benzene storage tank), dust exposure reduction from $13.21 \mathrm{mg} / \mathrm{m} 3$ to $0.26 \mathrm{mg} / \mathrm{m} 3$ (substitute with direct bulker unloading instead of manual bag unloading system), catalyst replacement activity to reduce nickel exposure from $33 \mathrm{mg} / \mathrm{m} 3$ to $<1 \mathrm{mg} / \mathrm{m} 3$ (local exhaust ventilation system at loading point), Noise exposure reduction from $96.2 \mathrm{dBA}$ to $85 \mathrm{dBA}$ by providing acoustic insulation, Heat stress reduction for workers working inside sea water pipe line by providing forced cool air ventilation system. Ergonomic improvement project of implementing vertical lifting machine at material storage location.

Discussion CASHe program at Reliance proves that team approach, creating awareness, positive attitude and implementation of innovative interventions are win-win prospect and makes good business sense. CASHe program is an endless journey of awareness and workplace improvements.

\section{MEDICHEM SYMPOSIUM: HOW EPIDEMIOLOGY CAN INFORM NON-LINEAR DOSE-RESPONSES FOR OCCUPATIONAL CARCINOGENS}

Kenneth Mundt*. Ramboll Environ, Amherst, Massachusetts, USA

\subsection{6/oemed-2018-ICOHabstracts. 1027}

Aim of special session Epidemiological evidence challenges the linear no-threshold default model for cancer risks. The methodological and regulatory implications are explored.

${ }^{1}$ Dr. Paolo Boffetta, ${ }^{2}$ Dr. Harvey Checkoway, ${ }^{3}$ Dr. Dirk Pallapies

${ }^{1}$ Icahn School of Medicine at Mount Sinai, New York, New York, USA

${ }^{2}$ University of California, San Diego, La Jolla, CA, USA

${ }^{3}$ Institute for Prevention and Occupational Medicine of the German Social Accident Insurance, Institute of the Ruhr Universität Bochum (IPA), Bochum, Germany 